\title{
The Intersection of the Scholarship of Teaching and Learning with Online Course Design in Teacher Education
}

\author{
Kathryn S. Lee, PhD \\ Assistant Professor, Department of Curriculum \& Instruction \\ Texas State University - San Marcos
}

This study employed a web-based survey investigating graduate students' perceptions of effectiveness of various learning activities in an online teacher education course designed to teach instructional strategies. Learner-centered evaluation allows for insights into the teaching and learning process, and learner satisfaction is particularly critical in determining quality in distance education. The findings would inform a redesign of the course with the goal to enhance learning, using students as evaluators. The students' ratings and comments of course activities are discussed, and implications related to course redesign are examined.

Nearly 4 million students were enrolled in an online course in higher education in the United States during the Fall 2007 semester (Allen \& Seaman, 2008). With the burgeoning growth and demand for collegiate online courses, it is imperative that we respond to the needs of online learners to ensure academic success (Moore, Sener, \& Fetzner, 2006). Studies that investigate and confirm that individual distance education courses support rigorous learning outcomes, effectively use available technology to improve pedagogy, and provide student satisfaction are essential to the scholarship of teaching and learning. This article recounts one such study focused on student learning and, in doing so, documents learning effectiveness in order to make the teaching and learning process public and to advance the practice of teaching (Hutchings, Babb, \& Bjork, 2002).

The purpose of the study reported herein was to replicate and substantiate the results of a previous study conducted by the researcher (Lee, 2009) to inform a redesign of a course. The intent was to investigate graduate students' perceptions of the effectiveness of various learning activities in

Studies that investigate and confirm that individual distance education courses support rigorous learning outcomes, effectively use available technology to improve pedagogy, and provide student satisfaction are essential to the scholarship of teaching and learning. an online teacher education course designed to teach instructional strategies for improving secondary teaching. The findings informed a redesign of the course with the goal of enhancing learning, using students as evaluators (Calloway, 2008; Cuthrell \& Lyon, 2007). We know that learner-centered evaluation allows for insights into the teaching and learning process (Cerbin, 1995), and that learner satisfaction is particularly critical in determining quality in distance education (Belfer, 2000). This study additionally addressed Shulman's three rationales for the scholarship of teaching and learning: professionalism, pragmatism, and policy (2000). As a teacher educator, I have the professional responsibility to ensure that an online course designed to teach and model effective instructional strategies does what it purports to do. Online courses in teacher education have the added responsibility of modeling "best practices" in online design and online facilitation due to a substantial increase of online courses offered in K-12 schools. Some of these teachers will likely become online facilitators themselves, as experts predict that online learning in K-12 schools will accelerate (Picciano \& Seaman, 2009). Furthermore, engaging in such inquiry and documenting the journey facilitates the sharing of our craft, resulting in a body of work that "becomes public, peer-reviewed and critiqued, and exchanged with other members of our professional communities so they, in turn, can build on our work" (Shulman, 2000, 49). Surveying the graduate students themselves to investigate their perceptions of the effectiveness of

InSight: A J ournal of Scholarly Teaching 
the online learning activities was a pragmatic approach designed to inform "efforts in the design and adaptation of teaching in the interests of student learning" (Shulman, 2000, 49). Also, this research provides a "policy" rationale, responding to standards of quality assurance in teacher education (National Council for Accreditation of Teacher Education, 2008) and distance education (Wang, 2006).

\section{Method}

\section{Participants}

At the end of the semester and after course grades had been calculated, I recruited participants who had been enrolled as students in the online graduate course, using the class roster with university e-mail addresses. An e-mailed invitation to 26 individuals yielded 24 participants. The invitation included the purpose of the research survey, the estimated time to complete it, explanations related to informed consent and confidentiality, the Institutional Review Board approval number, and a two-week deadline for completion. Table 1 summarizes the demographic characteristics of the participants.

Table 1: Demographic Characteristics of Participants $(\mathbf{N}=24)$

\begin{tabular}{|c|c|c|}
\hline Characteristic & $\underline{N}$ & $\%$ \\
\hline \multicolumn{3}{|l|}{ Age at time of survey (years) } \\
\hline $23-27$ & 7 & 29.2 \\
\hline $28-33$ & 11 & 45.8 \\
\hline $45-47$ & 2 & 8.3 \\
\hline $50-55$ & 4 & 16.7 \\
\hline \multicolumn{3}{|l|}{ Gender } \\
\hline Female & 16 & 67 \\
\hline Male & 8 & 33 \\
\hline \multicolumn{3}{|l|}{ Ethnicity } \\
\hline White & 18 & 75 \\
\hline Hispanic & 4 & 16.7 \\
\hline Asian & 2 & 8.3 \\
\hline
\end{tabular}

\section{Measures}

A survey was employed as the research tool to examine the students' perceptions of the effectiveness of the online activities, affording a process of examination and reflection, "viewing teaching and research as fundamentally dialogical activities" (Ritchie \& Goodburn, 1996, p. 76). The online course survey was created using SPSS mrlnterview (4.0), a browser-based authoring tool. This sophisticated tool afforded respondent data to be exported directly into SPSS, a data analysis software program. The survey was designed to gather basic demographic data on the participants and determine the graduate students' perceptions of the effectiveness of the online instructional activities. A categoric grid allowed respondents to quickly and easily rate a comprehensive list of the course activities. Several open-ended questions allowed respondents to personally comment on various aspects of the course activities.

\section{Results}

Participants rated each of the weekly activities in response to the question, "How effective were these learning activities in facilitating your learning of instructional strategies?" Point values for the responses were assigned as follows: 
excellent (1), good (2), fair (3), and poor (4). Means and standard deviations were calculated for each activity. Table 2 presents the graduate students' perceived effectiveness of the online activities from most effective to least effective, as demonstrated by the mean and standard deviation scores.

\section{Table 2: Rating of Online Activities by Number, Mean and Standard} Deviation, $\mathbf{N}=\mathbf{2 4}$

\begin{tabular}{|c|c|c|}
\hline Activity & M & SD \\
\hline Field Experience Portfolio: Construct lesson plan for video teach & 1.38 & .65 \\
\hline $\begin{array}{l}\text { Field Experience Portfolio: Construct portfolio notebook of field } \\
\text { practicum }\end{array}$ & 1.38 & .58 \\
\hline $\begin{array}{l}\text { Performance Assessment: Construct extended-type performance task } \\
\text { and assessment rubric in your content area }\end{array}$ & 1.50 & .98 \\
\hline $\begin{array}{l}\text { Field Experience Portfolio: Reflect on video teach, write reflection, and } \\
\text { upload to Live Text }\end{array}$ & 1.50 & .78 \\
\hline Field Experience Portfolio: Record video teach and burn onto CD & 1.50 & .78 \\
\hline Field Experience Portfolio: Conduct teacher interview & 1.54 & .88 \\
\hline Field Experience Portfolio: Analyze classroom observations & 1.54 & .88 \\
\hline $\begin{array}{l}\text { Mental Models About Teaching: View "First Day of Class" video and } \\
\text { categorize teaching behaviors }\end{array}$ & 1.62 & .77 \\
\hline $\begin{array}{l}\text { Active Learning: Watch "Jerry Seinfeld" and "The Mirror Has Two } \\
\text { Faces." Discuss effective and ineffective practices in forum }\end{array}$ & 1.63 & 1.14 \\
\hline $\begin{array}{l}\text { Questioning Styles and Strategies: Discuss "Common questioning } \\
\text { errors" }\end{array}$ & 1.63 & .77 \\
\hline $\begin{array}{l}\text { Building a Learning Community: Introduce self in "All About Me." } \\
\text { Include photo and welcome to classmates. }\end{array}$ & 1.67 & .70 \\
\hline $\begin{array}{l}\text { Cooperative Learning: Read, map, and summarize the } 5 \text { essential } \\
\text { elements of cooperative learning }\end{array}$ & 1.67 & .92 \\
\hline Mental Models About Teaching: Discuss "Seven Myths of Learning" & 1.71 & .75 \\
\hline $\begin{array}{l}\text { Motivation: Motivation Factors: Discuss influence of race, SES, } \\
\text { linguistic ability, religion, etc. }\end{array}$ & 1.71 & 1.12 \\
\hline $\begin{array}{l}\text { Learning Styles: Complete Index of Learning Styles Questionnaire and } \\
\text { analyze results }\end{array}$ & 1.75 & .74 \\
\hline $\begin{array}{l}\text { Motivation: Cognitive Interactions: Post thought-provoking questions } \\
\text { and responses to "Concepts of Ability and Motivation" }\end{array}$ & 1.75 & .85 \\
\hline Assessment: Instruction: Massaging the TEKS & 1.79 & .78 \\
\hline $\begin{array}{l}\text { Learning Styles: Claim research article and post responses to the } \\
\text { multicultural perspective discussion forum }\end{array}$ & 1.83 & .92 \\
\hline Mental Models About Teaching: Create a broadcast letter & 1.87 & .80 \\
\hline $\begin{array}{l}\text { Engaging Students: Create magazine cover as summary for "Making } \\
\text { Learning Real: Engaging Students in Content" }\end{array}$ & 1.87 & .85 \\
\hline $\begin{array}{l}\text { Engaging Students: Watch Newscast video clip and discuss } \\
\text { advantages and disadvantages of strategy }\end{array}$ & 1.88 & .99 \\
\hline $\begin{array}{l}\text { Culturally Responsive Pedagogy: Create ppt. presentation on Ch. } 12 \\
\text { "Addressing the Academic Needs of I mmigrant Students" }\end{array}$ & 1.92 & .93 \\
\hline $\begin{array}{l}\text { Cooperative Learning: View "Working Together" clips on Teaching } \\
\text { Alive CD and answer guided reading }\end{array}$ & 1.96 & .96 \\
\hline Quiz: Ch. 3: Lesson Planning and Assessment Objectives & 1.96 & .81 \\
\hline $\begin{array}{l}\text { Building a Learning Community: Post personal goals using SMART } \\
\text { criteria }\end{array}$ & 1.96 & .91 \\
\hline $\begin{array}{l}\text { Building a Learning Community: Post and discuss "Online Student } \\
\text { Readiness Survey" results }\end{array}$ & 2.00 & .72 \\
\hline Field Experience Portfolio: Analyze a textbook & 2.00 & .89 \\
\hline Personalizing Culture: Discuss personalization of culture. & 2.00 & 1.22 \\
\hline Student-Centered Instruction: Watch "Good Morning Miss Tolliver" & 2.04 & 1.12 \\
\hline
\end{tabular}

InSight: A J ournal of Scholarly Teaching 


\begin{tabular}{|l|c|c|}
\hline video clip and discuss in forum & & \\
\hline $\begin{array}{l}\text { Assessment: Students: Read "Lessons at the Kitchen Table" and } \\
\text { discuss deficit thinking and funds of knowledge }\end{array}$ & 2.04 & 1.33 \\
\hline $\begin{array}{l}\text { Personalizing Culture: Complete jigsaw of "Personalizing Culture } \\
\text { through Anthropological and Educational Perspectives." }\end{array}$ & 2.08 & 1.10 \\
\hline $\begin{array}{l}\text { Questioning Styles and Strategies: Observe questioning strategies in } \\
\text { "Teaching Alive" CD }\end{array}$ & 2.08 & 1.14 \\
\hline $\begin{array}{l}\text { Student-Centered Instruction: Choose graphic organizer to } \\
\text { summarize Ch. 7 "Reflective Teaching and Learning: Students as } \\
\text { Stakeholders" }\end{array}$ & 2.08 & 1.21 \\
\hline Quiz: Ch. 5: Assessment During Instruction & 2.12 & .99 \\
\hline $\begin{array}{l}\text { Culturally Responsive Pedagogy: Complete guided reading questions } \\
\text { to Ch. 10 "Effective Multicultural Teaching Practices" }\end{array}$ & 2.12 & .85 \\
\hline $\begin{array}{l}\text { Assessment: Students: Take quiz on Assessment text Chapters 1 and } \\
\text { 2: Breadth of Assessment and Learning About Pupils Early }\end{array}$ & 2.17 & .96 \\
\hline Learning Styles: Compare results of 2 different online LS inventories & 2.17 & 1.31 \\
\hline $\begin{array}{l}\text { Student-Centered Instruction: Complete graphic organizer Ch. 5 } \\
\text { "Interactive Practice for Learning: Beyond Drill" }\end{array}$ & 2.21 & 1.38 \\
\hline Active Learning: Identify the ABCCD components of an objective & 2.29 & 1.27 \\
\hline $\begin{array}{l}\text { Performance Assessment: Take quiz over Ch. 8 "Performance } \\
\text { Assessment" }\end{array}$ & 2.29 & .91 \\
\hline Cooperative Learning: Jigsaw Group Debriefing: How effective? & 2.29 & 1.23 \\
\hline $\begin{array}{l}\text { Building a Learning Community: Take "Course Information \& } \\
\text { Syllabus" quiz }\end{array}$ & 2.42 & .93 \\
\hline $\begin{array}{l}\text { Personalizing Culture: View "Teaching Alive" video clip on } \\
\text { contextualization and describe a unit in content area that exemplifies } \\
\text { "meaning making" }\end{array}$ & 2.46 & 1.62 \\
\hline $\begin{array}{l}\text { Cooperative Learning: Just for Fun: Watch "Emperor's New Groove" } \\
\text { video clip and discuss the tenets of cooperative learning }\end{array}$ & 2.58 & 1.59 \\
\hline $\begin{array}{l}\text { Cooperative Learning: Just for Fun: What would Johnson and J ohnson } \\
\text { say? }\end{array}$ & 2.67 & 1.47 \\
\hline
\end{tabular}

\section{Discussion}

\section{Context of Online Instructional Activities}

This teacher education course, Strategies for Improving Secondary Teaching, is required for a Master's degree in education and/or post-baccalaureate teacher certification, and the course is also a prerequisite for student teaching. The course utilizes a 30-hour field experience model, allowing graduate students the opportunity to bridge theory and practice (Brandsford, Pellegrino, \& Donovan, 1999). Units of instruction are organized into weekly learning modules (e.g., building a learning community, mental models of teaching, cooperative learning, etc.); to scaffold the learning, all the week's activities are bound in one location. The findings of this follow-up study were congruent with the findings of the previous study. Data from both surveys supported similar general categories of most effective and least effective activities.

\section{Most Effective Activities}

In response to the open-ended survey question asking the students to identify the most effective learning activity, the field experience activities were rated among the highest. As two students reported:

- $\quad$ "The portfolio process - I really enjoyed all the aspects of the classroom and my observation. The experience really showed me that I want to be in a classroom and I thought it was 
important to see other subjects beyond your content area. I wish I could have gone the whole semester; I did not want to leave."

- $\quad$ "I had a wonderful time with my field experience. I honestly wish it were longer than 30 hours. I wish it were more of an every week thing. It allowed me to look into the lives of teachers and see what their day-to-day activities were actually like. They allowed me to interject whenever I wanted and made me feel very comfortable. It also led to a possible job. The district wants to hire me on in a new school they are opening. Thanks to my field experience, I was given a wonderful opportunity!"

The students' field experience portfolio, submitted at the end of the semester, included a log documenting 30 hours in the field, a teacher interview, textbook analysis, classroom observations in three different content areas, a lesson plan (created in concert with the cooperating teacher), a "video teach" (videotaped teaching of the lesson plan), and video teach reflection. Other comments related to the value of the field experience included:

- $\quad$ "I think that the video teach process was the best because you get to think about integrating learned methods and reflect on it. The reflection piece is vital because the camera does not lie."

- $\quad$ "The video teach was my favorite because it got me out of the house and into my field that I enjoy. I learned the most from the teacher interview; getting information from experienced teachers is priceless."

- $\quad$ "I really enjoyed the field experience. I worked with a great $P$. E. teacher, and was actually able to get in the classroom and work with the kids. I learn better by hands on activities, so this was very helpful to me."

\section{Least Effective Activities}

In response to the open-ended survey question asking the students to identify the least effective learning activity, assignments and quizzes related to the weekly readings were among those most commonly identified. Several participants commented on their perceptions of the ineffectiveness of these learning activities:

- $\quad$ "I have never been a strong reader, so the articles, review questions, and quizzes took a lot of time."

- "Questions from chapters; I just don't like those kinds of assignments."

- $\quad$ "I did not like reading text and taking quizzes or answering guided reading questions. I was not motivated; I had to work hard to remain focused. But I do understand that reading and $Q \& A$ is required."

Regarding the online multiple choice quizzes over the reading content, the following responses were noted:

- "The chapter assessments, although usually straightforward, I am not a fan of the multiple-choice tests. I would much rather respond to questions in a written format."

- "I did not like the quizzes."

- $\quad$ "I didn't like the quizzes online. I took notes as I was reading and knew the info, but still didn't do very well on the quizzes. Assignments are a better way to test understanding." 


\section{Suggestions for Improvement}

Several respondents offered suggestions for improving the course via an open comment section of the survey:

- "Delete about $1 / 3$ of the weekly assignments. I felt overwhelmed with the quantity of work."

- "Have less work in the week and more meaningful projects."

- $\quad$ "Instead of assigning readings, have the students find their own valid articles to summarize and discuss. Have them present their own vision of teaching, pedagogy, and strategy."

- $\quad$ "I would love to have an actual chat session, like an active conversation but with time constraints and people's schedules, it's probably impossible."

Utilizing the student feedback collected from this survey and the previous one (Lee, 2009) provided valuable information on ways to improve the design of the course and the online learning experience for future students.

\section{Considerations for Redesign}

Although the overall high student ratings of the perceived effectiveness of the learning activities incorporated in Strategies for Improving Secondary Teaching indicate a strong original design, it is critical to examine, analyze, and improve upon the learning activities identified as needing improvement. Originally the course was co-created by a subject matter expert and an instructional designer, neither of whom had taught an online course. The logical "next step" was to investigate the course effectiveness through the lens of students who had completed the course and the faculty member who had taught it.

\section{Build on Strengths}

The field experience was perceived as the most valuable component of the course. In conjunction with students' suggestions for having fewer and more meaningful activities, decreasing the number of activities and integrating the course activities more closely with the field experience is warranted. Further study of the most "effective online strategies for integrating coursework and field experiences" (Knapczyk \& Hew, 2007) will improve the value of several course activities. Dykman and Davis (2008) caution that --

it is difficult for an instructor to judge workload levels in an online course. There is a real tendency to overload the student with work to make sure that an online course, which is potentially visible to other faculty and administrators, has a level of content and rigor equivalent to a comparable conventional course (159).

As the online facilitator of this course for several semesters and having graded the large quantity of course assignments, I agree that there are too many assignments. In his recommendation to "analyze and balance interactions" Hirumi warns that too many interactions can frustrate online learners, resulting in cognitive overload and an overwhelmed instructor (2003, p. 79).

\section{Integration \& Effective Use and Modeling of Technology Tools}

Although this online course was offered through the university's open source course groupware, which offers built-in technologies such as a discussion board, digital drop box, and wiki space, integrating the use of the prolific and easyto-use Web 2.0 tools is essential to model and practice the use of these innovative and $21^{\text {st }}$ Century technologies to enhance learning. For example, one of the suggestions for course improvement was to offer a chat, an activity resembling 
"more of an active conversation." One way to address this issue of personalization would be to utilize Tokbox (http://www.tokbox.com), a free video chat and video email provider. Students and the instructor would be able to video chat in "real time" if schedules allowed, and/or video emails could be recorded and sent asynchronously. Griffiths \& Graham (2009) recently found that using asynchronous video in an online course facilitated a sense of personal connection and immediacy between instructor and students. Using asynchronous video as a vehicle through which students could articulate and demonstrate their understanding of course readings would be a viable option to replace the quizzes and/or chapter questions. Furthermore, allowing the students a choice of formats would support different learning styles and the motivational aspect of andragogy (Pew, 2007).

\section{Sound Pedagogical Design}

The overall high ratings the students assigned to the various learning activities may be attributed to the course designers' commitment to sound pedagogical practice, as they followed Newlin \& Wang's (2002) recommendation that faculty in all disciplines apply American Association of Higher Education's Seven Principles of Good Practice in Undergraduate Education (1987) when designing online courses. The seven principles are:

1. Encourage contact between students and faculty

2. Develop reciprocity and cooperation among students

3. Use active learning techniques

4. Give prompt feedback

5. Emphasize time-on-task

6. Communicate high expectations

7. Respect diverse talents and ways of learning

These principles of "best practice" were incorporated into the design of the course. For example, contact between students and faculty was facilitated by the creation of weekly discussion board forums for dialogue among students and the instructor focusing on the concepts being explored. An "Assignment Clarification" forum was created as a central location for students to pose questions or concerns about assignments, field experience requirements, and other course-related concerns. Numerous interactive activities and media were incorporated into the design of the course to meet the diverse learning preferences of the students enrolled in the course. For example, video clips modeling the use of various instructional strategies in the classroom were employed; routine weekly activities included student-created learning artifacts as demonstration of their learning. I communicated high expectations by providing performance assessment rubrics outlining specific assignment criteria and provided weekly feedback to the students regarding their progress.

Incorporating student survey data as

formative feedback to improve a course design supports a student-centered learning

\section{Incorporating student survey data as formative feedback to improve a course design supports a student-centered learning paradigm.} paradigm. Additionally, integrating Web 2.0 technologies as powerful learning tools facilitates the evolution of effective online instruction and learning. The venue of scholarship of teaching and learning offers those who are dedicated to the advancement of teaching and learning a vehicle to document and share their research efforts and scholarly work. "Scholarship of teaching and learning supports our individual and professional roles, our practical responsibilities to our students and institution, and our social and political obligations to those that support and take responsibility for higher education" (Shulman, 2000, p. 52). 


\section{References}

Allen, I. E., \& Seaman, J. (2008). Staying the course: Online education in the United States. Retrieved April 2, 2009, from

www.sloanc.org/publications/survey/ pdf/staying_the_course.pdf

American Association of Higher Education. (1987). Seven principles of good practice in undergraduate education. Winona, MN: Seven Principles Resource Center, Winona State University.

Belfer, K. (2000). A learner-centered assessment of quality for online education: Course climate. World Conference on Educational Multimedia, Hypermedia and Telecommunications, 1,1265-1267.

Brandsford, J. D., Pellegrino, J. W., \& Donovan, S. (1999). How people learn: Bridging research and practice. Washington, DC: National Academy Press.

Calloway, C. A. (2008). Let students be your guide-as lesson evaluators. Retrieved J uly 3, 2008, from http://www.techlearning.com/showAr ticle. php?articlel $D=196605246$

Cerbin, W. (1995). Connecting assessment of learning to improvement of teaching through the course portfolio. Assessment Update, $7(1), 4-6$.

Cuthrell, K., \& Lyon, A. (2007). Instructional strategies: What do online students prefer? MERLOT Journal of Online Learning and Teaching , 3(4), 357-362.

Dykman, C. A., \& Davis, C. K. (2008). Online education forum - Part two- Teaching online versus teaching conventionally. Journal of Information Systems Education, 19(2), 157-164. Retrieved March 27, 2009, from the Ebsco database.
Griffiths, M., \& Graham, C. (2009). Using asynchronous video to achieve instructor immediacy and closeness in online classes: Experiences from three cases. In C. Crawford et al. (Eds.), Proceedings of Society for Information Technology and Teacher Education International Conference 2009. Chesapeake, VA: AACE.

Hirumi, A. (2003). Get a life: Six tactics for optimizing time spent online. Computers in the Schools, 20(3), 73-101.

Hutchings, P., Babb, M., \& Bjork, C. (2002). CASTL resources: An annotated bibliography of the Scholarship of Teaching and Learning in higher education. Retrieved April 2, 2009, from www.carnegiefoundation.org

Knapczyk, D. R., \& Hew, K. F. (2007). An analysis and evaluation of online instructional activities. Teacher Education and Special Education, 30(3), 167-182.

Lee, K. S. (2009). Listening to students: Investigating the effectiveness of an online graduate teaching strategies course. MERLOT Journal of Online Learning and Teaching , 5(1), 72-87.

Moore, J. C., Sener, J., \& Fetzner, M. (2006). Getting better: ALN and student success. Journal of Asynchronous Learning Networks, 10(3), 55-84.

National Council for Accreditation of Teacher Education. (2008). Professional Standards for the Accreditation of Teacher Preparation Institutions. Retrieved April 2, 2009, from http://ncate.org

Newlin, M. H., \& Wang, A. Y. (2002). Integrating technology and pedagogy: Web instruction and seven principles of undergraduate education. Teaching of Psychology, 29(4), 325-330. 
Pew, S. (2007). Andragogy and pedagogy as foundational theory for student motivation in higher education. InSight: A Journal of Scholarly Teaching, 2, 14-25. Retrieved March 27, 2009, from http://www. insightjournal. net

Picciano, A. G., \& Seaman, J. (2009). K-12 online learning: A 2008 followup of the survey of U.S. school district administrators. Retrieved April 2, 2009, from http://www. sloanc.org/publications/survey/index.asp
Ritchie, J., \& Goodburn, A. (1996). Collaborative inquiry in the teaching of writing theory and practice at the University of Nebraska-Lincoln. In Hutchings, Making teaching community property, 73-76. Washington, DC: American Association for Higher Education.

Shulman, L. (2000). From Minsk to Pinsk: Why a Scholarship of Teaching and Learning? The Journal of the Scholarship of Teaching and Learning, 1(1), 48-52. Retrieved March 27, 2009, from http://www.iupui.edu/ josotl/VOL_1/ NO_1/shulman_vol_1_no_1.htm

Wang, Q. (2006). Quality assurance - Best practices for assessing online programs. International Journal on ELearning, 5(2), 265-274.

Kathryn S. Lee is a teacher educator at Texas State University-San Marcos in the Department of Curriculum \& Instruction. She is committed to promoting a culture of diversity in education and responding to the unique needs of individual students within face-to-face and online learning environments. 
"The great aim of education is not knowledge, but action." Albert Einstein 